\title{
Reviews
}

\section{Nigel Rothfels}

\section{Zoo Stories}

John Bierlein and the Staff of HistoryLink, Woodland: The Story of the animals and People of Woodland Park Zoo. Seattle: HistoryLink, 2017. 200pp. \$29.95 pb.

Andrew Flack, The Wild Within: Histories of a Landmark British Zoo. Charlottesville: University of Virginia Press, 2018. 272 pp. $\$ 39.50$ hc; $\$ 39.50$ e-book.
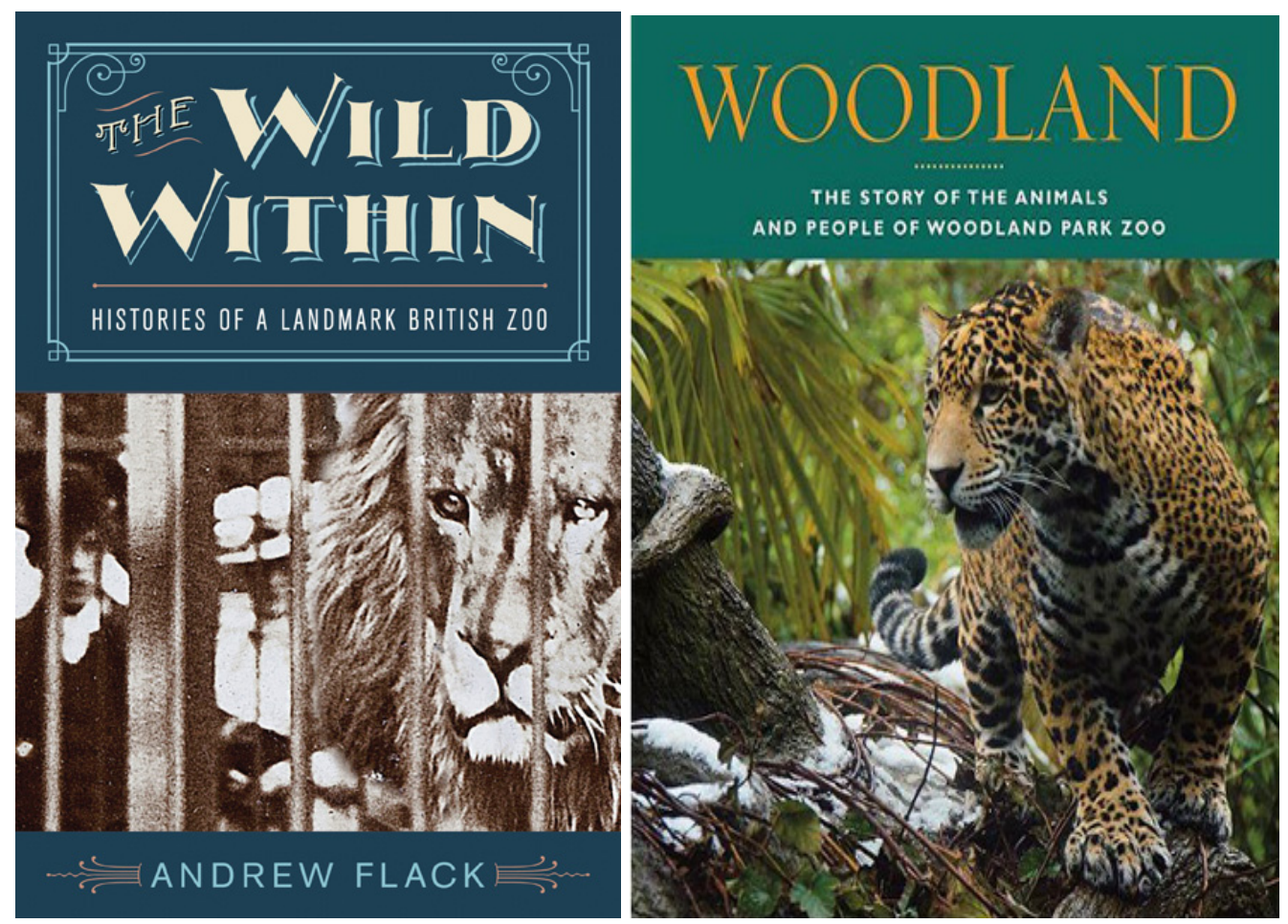

A quick description of Woodland: The Story of the Animals and People of the Woodland Park Zoo might look something like: "a lavishly illustrated and richly detailed history of one of America's most lauded zoos - an account that will be particularly enjoyed by the zoo's patrons and enthusiasts who will undoubtedly find it prominently showcased in the 'ZooStores' conveniently located at both major exits from the park." The book is larger format $\left(9^{\prime \prime} \times 10^{\prime \prime}\right)$ with two columns on a page and illustrations on every spread until the end, where one finds: a list of people "whose contributions made this book possible," an appendix of awards the zoo has received from professional associations 
since the 1970s, a three-page list of zoo board members and members of a zoo commission in the mid-1980s, a bibliography of about 40 titles, a list of photo credits, and a brief index. This is a book designed to be prominently displayed on a coffee table, and there is nothing wrong with that.

But let me return to two words in that quick description: "lavishly illustrated." They are lavish, but they are also entirely predictable. The cover of the book, for example, shows an up-close photograph in oranges and greens of a jaguar in the forest. The animal is walking toward the camera, but looking just off to the side as if something has caught his attention. But this isn't the South American jungle. There is a little snow on the ground and those plants are a mix of synthetics and species more at home in temperate environments. This is a jaguar in the north - in captivity - but there are no bars, no mesh, no food bowl, no straight lines, no people. It is a classic shot of a popular modern genre of zoo photograph, of photographs visitors to zoos are always trying to take themselves. It looks like the "wild" but then clearly isn't. It is the sort of photograph loved by zoo marketing departments and directors, the fans of zoos, and probably even the designers of the exhibit (in this case, the Portico Group in Seattle). There are many photographs like this in the book - mostly full page. Then there are the inevitable photographs of children looking with wonder, often through a barely-perceptible wall of glass, at "nature." Then there are the older, black-and-white photographs - often images from postcards - that are used in the beginning chapters to tell the story of the early years of the zoo. These images are more about whole exhibits with people in the foreground. They are about "visiting the zoo" but they are clearly from an earlier, somehow quaint era. Finally, there are the images of people and animals who have proper names - the personalities, both human (especially former directors and longterm staff) and animal, who mark points in the long march of the zoo from a small amusement park to a what is now described as a leading world center of environmental education and conservation.

The main author of Woodland is John Bierlein, who worked in education and interpretation at the zoo for over twenty years and appears to have taken over the book project from another employee, Dana Payne. Somewhere along the line, "staff" at HistoryLink, “a 501(c)(3) not-for-profit corporation established in 1997 to pioneer innovative approaches to historical research, education, and publishing" (https://www.historylink.org/File/20001), became involved. HistoryLink holds the copyright for the book and the whole project would really be best understood as a work of public history. Indeed, it is easy to imagine how the book might be translated into the sort of exhibits one increasingly finds in libraries and other civic locations. The book

Humanimalia: a journal of human/animal interface studies

Volume 11, Number 2 (Spring 2020) 
tells a local story for a local audience very well. It is organized in a clear chronology and introduces readers to the main personalities that have shaped the institution since it was founded in 1899 . We read about the directors and their efforts to advance the zoo in collaboration with or open opposition to city government. We are introduced to heroic visionary architects and thinkers (especially David Hancocks and Jon Coe) who had the audacity to think about new futures for the zoo. And, of course, we read about the locally famous animals remembered for one reason or another. All of this is predictable, and it is all good reading, too. Bierlein, HistoryLink, and the Woodland Park Zoo should be commended for producing a work that is informative, thoughtful, and the sort of record that would make any community proud of its zoo and its history.

Andrew Flack's The Wild Within: Histories of a Landmark British Zoo is another kind of book entirely. Recognizing, of course, that book titles are as much a marketing decision as anything else, one should pause for a moment on that subtitle. It is "histories" because Flack is not interested in telling a single chronological account of how a small provincial zoo that opened 1836 managed to survive various heydays, economic catastrophes, world wars, and waves of criticism to become the fifth oldest zoo in the world. And it is "a Landmark British Zoo" because, in the end, although Flack's account is anchored in the animals and people of the Bristol Zoo, he wants to tell a more general story about exotic animals and spectacles in Britain over the last two centuries.

Flack does interweave a chronology of the Bristol zoo, divided into three fairly discrete periods. In the early years, the focus was to build an exhaustive and taxonomically organized collection of animals for the benefit of science and the edification of the public. Then, in the latter part of the nineteenth century and through the post-WWII period, the zoo participated in a growing sentimentalization of zoo animals as, according to Flack, the public became more comfortable with Darwinian ideas of continuities between humans and animals. Finally, beginning in the last decades of the twentieth century, the zoo began to tell larger stories of species in crisis by highlighting the lives of individual animals as ambassadors of the wild.

Rather than organize his book chronologically, though, Flack tells his story by describing "layers" of relationships, representations, and interactions between people and animals at the zoo. These layers, Flack argues, are always present at the zoo and in individual exhibits and are stressed to lesser or greater degrees depending on the time, circumstances, and even the individual animals on display. The layers, for Flack, include: 1) animals as articles of value for commerce; 2) animals as characters in

Nigel Rothfels -- Zoo Stories 
performance and entertainment; 3) animals as repositories of knowledge; 4) animals as anthropomorphized "shape-shifters" that somehow seem both animal and human; and 5) animals as entities that challenge and resist the objectifying gaze of the audience and insist on their subjective agency in the world. Each of these layers forms a chapter of the book and through them Flack presents more than a history of the Bristol Zoo; he provides a theoretical structure for understanding how people in a wide variety of contexts build their understanding of the animals of the world.

Flack's approach does tend to de-emphasize the distinctive and particular character of the Bristol Zoo. Although, we meet many of the animal and human personalities of Bristol, and learn, too, about particularly innovative exhibits (including the first nocturnal house in any zoo), I never really got a sense for the landscape and feel of the Bristol Zoo. In contrast, reading Bierlein's Woodland leaves an impression of almost having visited the zoo repeatedly over the last 120 years. Woodland is more about a very particular zoo; The Wild Within tells perhaps a more important story about zoos in general by focusing on a historically important zoo that has been largely neglected in scholarship. There are strengths to both approaches, but Flack's will, in the end, give one a deeper understanding of the Jaguar Cove exhibit at Woodland Park Zoo than finding out that the resident jaguar had to be trained to swim in the exhibit so a good photograph could be included as part of an application for a prize from the Association of Zoos and Aquariums.

Woodland, as Betty White writes in her "Foreword," is "an animal lover's delight," a "time-traveler's visit to the Woodland Park Zoo." The Wild Within, by contrast, is for a reader who appreciates the work of a historian who has spent years sifting through a deep and rich array of archival materials to tell a larger story of animals in modernity. I enjoyed both of these books and recommend them to anyone interested in thinking more about the peculiar cultural phenomena of zoos.

Humanimalia: a journal of human/animal interface studies

Volume 11, Number 2 (Spring 2020) 